\title{
Symptom Control in Survivorship Care
}

Urinary symptoms, post treatment, are a significant problem within this cohort. This is highlighted by [1], assessed 22 participants (a quasi-experimental: feasibility study) involving 7 weeks of group and individual sessions for patients post radiotherapy with urinary side effects. Outcomes were analysed via a questionnaire based on urinary symptoms. These were assessed before and after the intervention at baseline and 4 months. International Prostate Symptom Scores were used. The results suggest cognitive and behavioural self-management intervention can improve lower urinary tract symptoms (LUTS) in men who have had radiotherapy treatment for prostate cancer (Moher ' $\mathrm{B}$ ' quality, [2]). This also highlights the role of secondary care in the survivorship phase. A partnership between primary and secondary care, is central to survivorship. It also highlights patient self-efficacy that can develop with incredibly simple interventions. This study is reliable as there is a clearly focused research question, with a clearly defined sample of patients, and minimal loss to follow-up. Clear objectives were present, with unbiased outcome criteria. The outcome had been met over this period of time, however there were no confidence intervals. This study is relevant to our study, as it is with a similar cohort of patients. These results lead to suggesting that and are also applicable to similar groups of patients.

\section{References}

1. Jones LW, Hornsby WE, Freedland SJ, Lane A, West MJ, Moul JW, Ferrandino MN, Allen JD, Kenjale AA, Thomas SM, Herndon IJE, Koontz BF, Chan JM, Khouri MG, Douglas PS, Eves ND. Effects of nonlinear aerobic training on erectile dysfunction and cardiovascular function following radical prostatectomy for clinically localized prostate cancer. Eur Urol. 2014;65:852-5.

2. Uetani K, Nakayama T, Ikai H, Yonemoto N, Moher D. Quality of reports on randomized controlled trials conducted in Japan: evaluation of adherence to the CONSORT statement. Intern Med. 2009;48(5):307-13. 